\title{
Wheel maintenance in rolling stock: safety challenges in the defect detection process
}

\author{
Maria Mikela Chatzimichailidou* \\ LRF Transport Risk Management Centre, \\ Imperial College of London, UK \\ and \\ Centre for Systems Engineering and Innovation, \\ Imperial College London, UK \\ Email: mmcsyseng@imperial.ac.uk \\ *Corresponding author
}

\section{Alberto Martinetti}

Design, Production and Management Department, University of Twente, The Netherlands

Email: a.martinetti@utwente.nl

\section{Arnab Majumdar}

LRF Transport Risk Management Centre, Imperial College of London, UK

Email: a.majumdar@imperial.ac.uk

\section{Leo A.M. van Dongen}

Design, Production and Management Department, University of Twente, The Netherlands and

Netherlands Railways, The Netherlands

Email: leo.vandongen@ns.nl

\section{Washington Yotto Ochieng}

Centre for Transport Studies, Department of Civil and Environmental Engineering, Imperial College of London, UK

Email: w.ochieng@imperial.ac.uk 
Abstract: The proper and timely maintenance of railway rolling stock is essential for the safety of railway operations. Inaccurate inspection can lead to inadequate repair of defects and to great safety challenges in respect to the entire railway system. The detection and repair of any defect, such as cracks, in the wheels prior to a failure can significantly reduce train derailments and improved operational performance. This paper examines the wheel maintenance process in maintenance depots in the Netherlands on the basis of literature review, observations and interviews. First, it highlights various detection methods, including the risks of the incorrect detection of a flawed wheel profile. This paper introduces a flowchart as a concise illustration of the maintenance process; that is, both the detection and treatment of defects. With this in hand, the authors, as well as anyone involved in maintenance, are able to identify the points where the process is vulnerable and may be prone to incidents/accidents. Based on this procedure, improvements to the current wheel maintenance process can be proposed. The method that the flowchart is based on is also presented herein, along with the findings obtained throughout its steps.

Keywords: maintenance; safety; wheel defect; rolling stock.

Reference to this paper should be made as follows: Chatzimichailidou, M.M., Martinetti, A., Majumdar, A., van Dongen, L.A.M. and Ochieng, W.Y. (2018) 'Wheel maintenance in rolling stock: safety challenges in the defect detection process', Int. J. System of Systems Engineering, Vol. 8, No. 4, pp.387-397.

Biographical notes: Maria Mikela Chatzimichailidou is a Postdoctoral Research Associate at the Imperial College London. Previously, she was at the University of Cambridge, working with the NHS on Human Factors. She holds a Master's and PhD in Systems Engineering and Safety. Her publications are on the enhancement of systems safety and performance in transport, infrastructure, unmanned systems and healthcare. She is a member of the Institution of Engineering and Technology (IET) and invited as a member of the IET Aerospace Executive Team.

Alberto Martinetti is an Assistant Professor in the chair of Maintenance Engineering within the Department of Design, Production and Management. $\mathrm{He}$ is a member of the maintenance research centre TIME - Twente is Maintenance Excellence. He holds a Master's in Geo-resources and Geo-technologies Engineering and $\mathrm{PhD}$ in Environmental and Land/Safety and Health at the Polytechnic of Turin.

Arnab Majumdar is the Lloyds Register Foundation's Senior Lecturer in Transport Risk Management and Director of the Transport Risk Management Centre at the Centre for Transport Studies, Imperial College London. In 2003, he completed his $\mathrm{PhD}$ on the Estimation of Airspace Capacity in Europe at Imperial. He is also a Chartered Engineer.

Leo A.M. van Dongen has worked for the Netherlands Railways (NS, 100\% state owned) for over 30 years. He is the Chief Technology Officer (CTO), responsible for the asset management of the rolling stock fleet, workshops and maintenance equipment. He is also a Professor in Maintenance Engineering at the Faculty of Engineering Technology, from the Department of Design, Production and Management at the University of Twente. After his studies in mechanical engineering, he completed his doctoral research at the Eindhoven University of Technology on energy efficiency of drive trains for electric vehicles. At DAF Trucks, he was active in the development of diesel engines. 
Washington Yotto Ochieng is the Head of the Centre for Transport Studies and Chair of Positioning and Navigation Systems in the Department of Civil and Environmental Engineering at Imperial College London. He is also the Director of the Imperial College Engineering Geomatics Group. In 2013, he was elected Fellow of the Royal Academy of Engineering in recognition of his exceptional contribution to engineering.

\section{Introduction}

Modern infrastructures are normally classified as a system-of-systems ( $\mathrm{SoS})$ due to some distinctive features (Filippini and Silva, 2014; Sousa-Poza et al., 2008).

Among modern infrastructures, railways is certainly one of the most complex systems created by humans for humans, involving nearly every branch of engineering, from the power generation and its distribution to the control electronics, heavy structural engineering to human factors and geophysics to the global positioning system (GPS) (Institution of Mechanical Engineers, 2015). It is perhaps the ultimate engineered system and therefore bringing all the system components together and making them work - safely and optimally - poses a great challenge for the railway industry (Institution of Mechanical Engineers, 2015).

Railway systems are comprised of complex mechanical, electrical and electronic systems with a multitude of moving parts. Within this highly technological and engineered accumulation of systems, humans are responsible for ensuring the integrity of the system and making it work efficiently and reliably. Thus, along with the physical system (e.g., technology, rolling stock, infrastructure, etc.), railway systems also incorporate operational issues and services (e.g., timetabling, pricing, integration with other modes of transport), as well as system properties. These are usually emerging and arising from the interactions between humans (e.g., operators, customers, stakeholders) and technology. Typical examples of emergent properties are safety (Leveson, 2011); reliability of services; financial viability; resilience and sustainability; reduced carbon footprint (Karcanias, 2015).

With this in mind, railways can be considered as a system-of-systems and their overall safety depends on several factors including, rail traffic rules, infrastructure and rolling stock reliability, organisational safety management and human factors (Kyriakidis et al., 2015).

Given its complexity (i.e., procedures and interactions among its subsystems) and even if the definition of complexity is not always clear (Efatmaneshnik and Ryan, 2016), to examine a railway system in its entirety poses considerable difficulties. Willcox et al. (2011) agreed on defining the complexity as the ability of the system to produce unexpected states, drifting from the design phase. Consequently, this paper focuses solely upon railway maintenance, given that railway maintenance is less researched compared with railway operations. Railway maintenance is highly human-centric and human factors are mainly involved in crucial decision-making, such as the detection and analysis of wheel crack severity and its necessary treatment. This leads to questions like how much material should be removed from a wheel profile in order for the train to be ready to be put back in service without any safety risk that must be answered safely by the maintenance personnel. 
This paper presents an illustration of the process of inspecting, detecting and treating defects in wheel profile. Moreover, it presents the procedure that the authors followed in order to create the corresponding flowchart. The aim is to show the various stages of defect inspection and detection, along with the paths through which inadequate manipulations - both from humans and automated systems - may occur and, in turn, lead to safety risks, impacting at the same time the safety (Zhang et al., 2014) of the entire system, like in the case of derailments (Singh and Kumar, 2015).

Previous literature on wheel maintenance primarily concerns the profile of the wheel in terms of damage tolerance and fatigue (Gerdun et al., 2007; Zerbst et al., 2005), geometry (Zhang et al., 2014) and fracture mechanics (Zerbst et al., 2005). With this regard, Singh and Kumar (2015) evaluate human error probability in order to reduce the likelihood of errors occurring within a system. Singh and Kumar (2015) highlight elements of the system (bogie, wheel-set etc.) and discuss how a decline in human performance may lead to errors in maintenance tasks.

In contrast to the literature, this paper takes the first step towards engaging with a more holistic approach that will provide a platform to consider the organisational issues that may lead to human errors, as symptoms of a poor-designed system and not as direct causes for incidents/accidents. In addition, this paper probes the procedures, policies, requirements and tools in place, since they may create an environment prone to the decay in human performance. Hence, human performance decay can be seen as the result, and not as the cause, of an adverse event. Finally, this paper makes no use of statistics, for the reason that its aim is to find defects among assets before they reach the point of becoming a failure (Palo et al., 2013).

\section{Maintenance and flawed wheel profile}

Well-organised operational maintenance processes are an absolute necessity for keeping rolling stock performance at the desired levels (van Dongen, 2015). Long withdrawal of the fleet has a great influence on the cost and quality of services.

The authors argue that low human performance during the wheel maintenance process (that is disassembly; inspection; maintenance; assembly; re-profiling; installation) may not only impact the reliability of the wheels at a local level (i.e., the wheel break itself), but may also cause degradation to the overall levels of safety and eventually lead to a train accident, with derailments being a typical example.

Figures reveal that wheel cracks, along with other defects (e.g., eccentricities, discrete defect, periodic non-roundness ${ }^{1}$, non-periodic (stochastic) non-roundness, corrugation, roughness, flat, spalling and shelling), are one of the most significant issues in maintenance. Railway wheel cracks exposed to rolling contact loads and residual stresses originate from wheel flats as induced by wheel/rail sliding (Wallentin et al., 2005). Wheel damage occurs as cracks initiate and grow at or below the surface of a wheel and can gradually lead to wheel breakage, while the flawed wheel is gradually exposed to loads.

According to the Joint Sector Group (2012) the percentage of events for derailments due to wheel-set damages in Europe was estimated to be $31.8 \%$ in 2012 based on failure mode effects analysis (FMEA) and fault tree analysis (FTA). 
Under the same notion, the European Union Agency for Railways (2014, 2016) considers broken wheels as a precursor to rail accidents, being the only one that refers to maintenance, while other precursors such as SPADs apply to operations (European Union Agency for Railways, 2014, 2016). Precursors to accidents are indicators of incidents that under specific circumstances could lead to accidents, with derailments being the most severe.

Aside from the figures that reveal the criticality of maintaining wheel cracks, wheel maintenance is also crucial (Zhang et al., 2014; Singh and Kumar, 2015), as wheels constitute a large part of the rolling stock (Palo et al., 2013) and because they suffer from deterioration with usage and age (Zhang et al., 2014). The wheel profile determines the stability of a vehicle, and the rate of wheel surface wear determines the length of a wheel's life, as well as its behaviour. Thus, effective maintenance will increase the wheel's life (Palo et al., 2013), may prevent safety and quality failures and increase the overall performance as a consequence.

\section{Main focus of research}

The most safety-critical parts of rolling stock, such as wheels, are treated in maintenance depots. For the reasons presented in the previous section, this piece of work focuses on wheels.

In depots, the technical state of the relevant systems is measured in order to determine the need for further action and to predict (if possible) any future malfunction. Improving human factors is an important aspect of safety in railway maintenance because inspections are mainly based on operators' experience. This is particularly the case in depots, where - at least when compared to rail operations or the maintenance of rail tracks (Hodge et al., 2015; Meixedo et al., 2015) - there is often little in the way of technology to assist human personnel in their decision-making. This conclusion was backed up by the authors' observations in two maintenance depots (i.e., Leidschendam and Haarlem, NL), and was asserted by maintenance technicians and safety engineers in the Netherlands railways.

In the depots visited by the authors, maintenance on wheel-sets is undertaken in two stages: first, maintenance technicians detect the wheel defects in rolling stock, and subsequently they decide how and to what extent they are going to treat the defects in order to put the train back in service.

As shown in Figure 1, the authors have drawn a flowchart, which represents an indicative wheel defect detection process before the train is returned to the depot in order to treat the detected defect. Figure 1 is the essence of this work and hence explained in more detail in Sections 4 and 5.

\section{Method of flowchart development}

Figure 1 is an adaptation of the wheel defect detection process introduced by Palo et al, 2013), but is also based on multiple sources of information combined by the authors. These are the: 
- review of the literature mainly related to the overall railway maintenance and wheel defect detection

- observation of the maintenance procedures undertaken by maintenance technicians and experts within a depot in Leidschendam, the Netherlands

- semi-structured interview with the chief of the depot in Leidschendam

- semi-structured interviews (and questionnaires prior to face-to-face contact) with two System Engineers (see the Acknowledgements section) at the Netherlands Railways (Nederlandse Spoorwegen $-\mathrm{NS}^{2}$ ) headquarters in Utrecht, the Netherlands.

Figure 1 Overall detection process of possible wheel defects

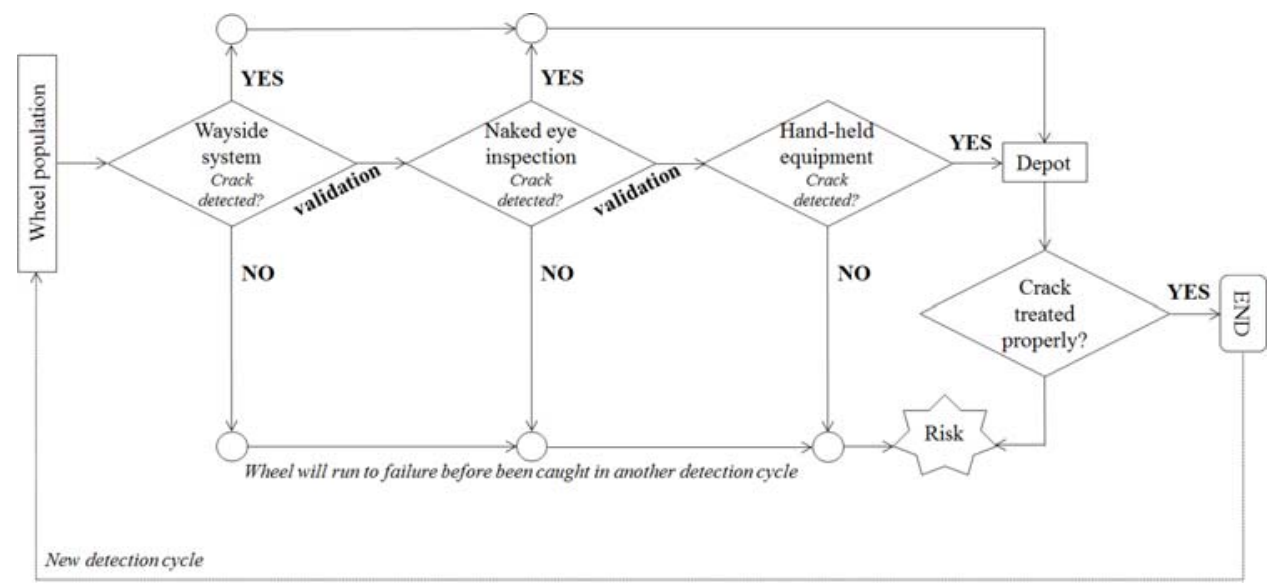

Figure 2 Method of flowchart development

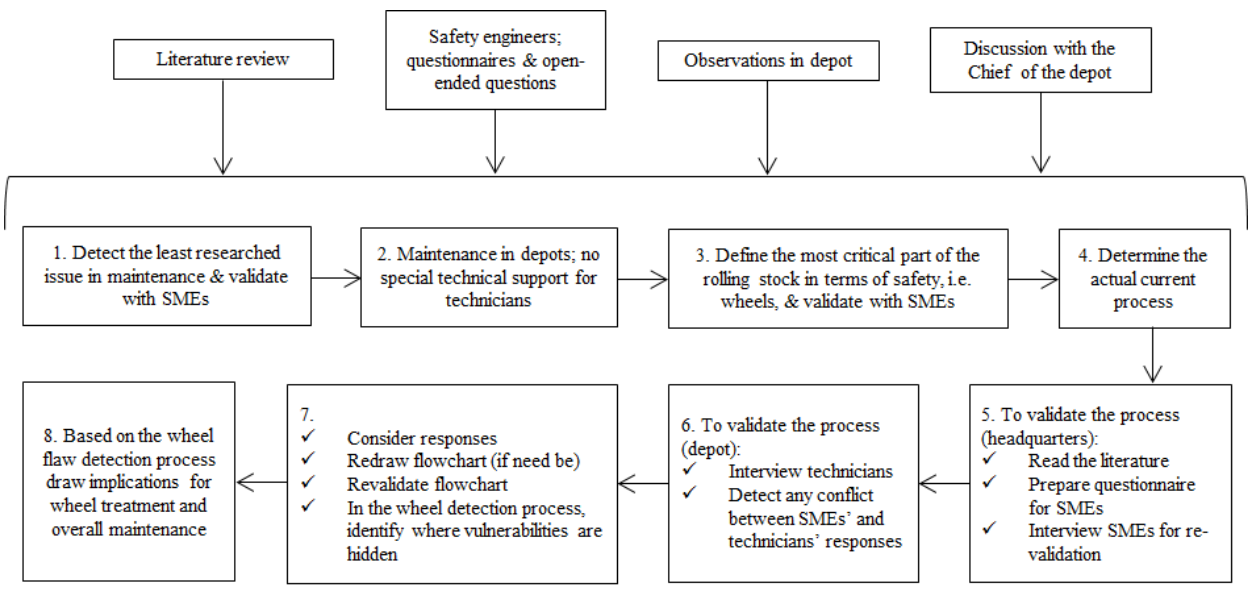

Figure 2 incorporates those sources of information and explains the development of the flowchart step-by-step in Section 5. During the development of this flowchart and throughout every step of this process, the research team were obtaining useful findings for the detection of wheel defects and their maintenance. Thus, due to the tight coupling 
between the flowchart development and the results from its' step-wise process, in Section 5, the authors elaborate on the tasks performed in each step and the corresponding conclusions they draw.

\section{Results of the method and the overall research}

At the beginning, the research team performed a literature review to detect the least researched issue in maintenance (Figure 2, Step 1). Depending on the part of the train under examination, inspection and treatment may take place at monitoring stations, at rail yards or in wagon workshops, i.e., depots.

The literature indicates that maintenance in depots is the least researched topic (Step 2). One possible reason is that inspection is mainly based on operators' experience. Moreover, technical support is either absent or not reliable enough. The Lloyd's Register Foundation (2015) in their Foresight Review of Structural Integrity and Systems Performance points out that it is important to ensure that defect detection and characterisation has a margin for error that is near zero. However, the development of more reliable and higher-resolution non-destructive examination technology has cost implications and is difficult to sustain at the moment.

Furthermore, the authors identified wheels as one of the most critical parts of the rolling stock because they determine the stability of the entire train (Step 3). After having detected wheel maintenance as one of the most critical issues, both in terms of safety and human factors, they asked four railway subject matter experts (SMEs) to validate this conclusion (Step 3). All the SMEs have over twenty years of experience both in academia and industry in the Netherlands and Sweden. The questions were semi-structured and the interviews were done over two one-hour teleconferences.

The next step was to determine the current process of wheel maintenance (Step 4). In order to do this the authors examined the related literature, such as academic papers and reports published by official railway bodies, and designed a questionnaire for the SMEs (Step 5). These SMEs were the same as the two who were interviewed in Step 3. The questions were directed towards eliciting information about the actual procedure of maintaining wheels. The questionnaires were sent via email to two system engineers. They were selected based on their role (i.e., system engineers), status (i.e., senior position) and experience in the respective field (i.e., five years). Based on their responses and on the processes presented in Palo et al. (2013), the authors developed the first version of a flowchart that depicted the detection process of wheel defects. Then, the authors visited the headquarters (Step 5) of the railway operator and a maintenance depot (Step 6) in the Netherlands. Firstly, in the headquarters they validated that first version of the flowchart for the defect detection process through a half-day structured discussion with senior engineers. Subsequently, the authors visited one of the biggest maintenance depots in the Netherlands, (i.e., Leidschendam), in order to compare the results obtained from senior engineers with the answers given by two maintenance technicians.

Both engineers and technicians indicated the same stages of maintenance (as in Figure 1), though, differences were found in the specific tasks executed while treating the wheels; for example, how deep should the tool penetrate the material in order to remove wheel cracks safely? One of the senior engineers explained, "the technical department decides what needs to be done, but how this is going to be done is decided by the workshops and differs among workshops". Such cases were not taken into account for the 
creation of the flowchart as it portrays the inspection of the wheels rather than the treatment of possible defects. The treatment is part of will be studied in detail in subsequent research.

Hence, given that both engineers and technicians agreed on the general stages of the maintenance process, the authors produced the final version of the flowchart (Step 7). Engineers then revalidated the last version of the process. Having a concise illustration of the maintenance process in place, the authors were able to identify the points where the process is vulnerable and may be prone to incidents/accidents (Step 7).

Finally, implications of the impact of inadequate wheel inspection were also outlined (Step 8 ). The aim of this was to identify hazardous scenarios arising from the process and the interactions among the different steps taken.

These steps led to the creation and validation of the flowchart depicted in Figure 1. This flowchart is useful for two reasons:

1 it illustrates in a simple way the various layers of control, in an attempt to detect wheel defects before the fleet is driven to the depot for further maintenance and thus prevent a serious safety drift; that is, accumulation of events that produce a gradual drift towards failure (Dekker et al., 2011)

2 it gives an overview of the maintenance process and helps those involved to be vigilant as to where a wheel defect may be missed or inadequately treated, exposing the train to risks and safety drift.

Such an illustration facilitates a shared understanding among all stakeholders.

Examples of scenarios of missed defects in wheel maintenance may be where the wheel surface defect is:

- Undetected by the wayside monitoring system, such as GOTCHA. ${ }^{3}$

- Detected by the wayside system but is not validated in the naked eye inspection performed by maintenance technicians.

- Detected by the wayside system, validated in the naked eye inspection but not validated in the hand-held equipment inspection performed by maintenance technicians. Checks with the use of hand-held equipment, such as portable ultrasound machines, are usually performed when there is disagreement between the findings of the wayside system and the naked-eye inspection, or among different technicians that inspect the same wheel for defects but reach conflicting conclusions.

- Detected by the wayside system, validated in both naked eye and hand-held equipment inspection, but is not treated properly by maintenance technicians in the depot.

Hazardous scenarios like the above-mentioned are risky situations and raise safety concerns for the entire system; for example, when a train is put back in service without a full repair of the defect in the wheels.

Thus, such an illustration may help safety engineering and maintenance experts set up safety mechanisms to apply more strict procedures that complement or extend existing ones, especially in complex systems, such as railways. The following section outlines the development of the flowchart. 


\section{Discussion}

In this paper, a flowchart representing a structured maintenance process was introduced as a means of depicting the steps among the various levels of inspection until the treatment of defects in depots. Figure 1 offers a clear and direct way to target the vulnerable stages of maintenance, along with their interactions. The hazardous scenarios, based on this preliminary research, reveal the need to determine the factors that either directly or indirectly led to errors in wheel maintenance.

Moreover, the on-going discussions with NS and personnel at maintenance depots have highlighted the need for a reliable, software-based tool that can assist railway organisations to assess the performance of their maintenance personnel and define the factors that mostly affect this performance. The design of such a tool goes beyond simply assessing the factors affecting performance to considering the needs of the users, its appropriate graphical user interface and its robustness in the maintenance workplace. The current lack of any such tools for railway maintenance personnel means that there is a great opportunity for such a tool in the global railway marketplace, which in turn will increase the safety of railway maintenance through improving human performance.

Thus, future research includes the creation of monitoring tools for predicting maintenance needs (Palo et al., 2013), not only in terms of treating the mechanical parts, but also assessing and improving human performance, as well as directing resources more efficiently towards the development of smart and effective solutions to reduce human error.

The expected benefits in regard to maintenance are as follows:

- railway industry and relevant stakeholders will be provided with a tool to be used in short- to medium-term maintenance plans based on scenarios of missed defects in wheel maintenance, like those presented previously in Section 2

- regulatory authorities and industry bodies will have information of the factors that impact maintenance and the nature of this impact; new codes of practice and regulations may also be introduced

- railway organisations, train and maintenance operators will be supplied with a tool that can be used on regular basis to assess the performance of their personnel and define the factors that mostly affect the personnel's performance

- academia and research institutes will be supplied with a novel and validated methodology to study human error and the contributing factors, so as to perform and improve safety assessment research.

\section{Conclusions}

This paper represents the first in a series, which will examine the overall process of wheel maintenance in depots and focus on the impact of human factors in the safety decisionmaking.

This paper provides a high-level illustration of the wheel maintenance procedure. This illustration was based upon observations and discussions with the relevant SMEs of NS. The aim was to pinpoint the crucial points in terms of risk and safety. Such an 
illustration can be used as a means for raising the awareness of stakeholders on the inherently vulnerable processes, help them review the current procedures, plan and employ measures to prevent problems and conflicts.

The results will serve as the basis of a more structured approach for reducing the impact of human errors in maintenance operations than at present. Consequently, future research will quantify the consequences of those errors in terms of wrong wear wheel assessment and lost material during the re-profiling procedure. To obtain this, the research team will analyse further maintenance depots in the Netherlands as well as investigate the number of factors that either directly or indirectly lead to errors in wheel maintenance by means analysing questionnaires completed by frontline managerial and maintenance employees in the Netherlands.

\section{Acknowledgements}

The paper was made achievable through the contribution in terms of data, technicians, experts and resources provided by Netherlands Railways (NS). In particular, the authors want to thank two System Engineers Gerben van Ulden and Ger de Vries for their support. Also, the authors are grateful to Mr. Edwin Schoumans, Technical Manager of the Department of Bogie Maintenance, who gave them access to the maintenance depot in Leidschendam, as well as the Chief of the Depot who provided them with much detail on the strengths and weakness of maintenance as done currently in the Netherlands.

\section{References}

Dekker, S., Cilliers, P. and Hofmeyr, J.H. (2011) 'The complexity of failure: implications of complexity theory for safety investigations', Safety Science, Vol. 49, No. 6, pp.939-945.

Efatmaneshnik, M. and Ryan, M.J. (2016) 'A general framework for measuring system complexity', Complexity, Vol. 21, No. 1, pp.533-546.

European Railway Agency (2014) Railway Safety Performance in the European Union [online] http://www.era.europa.eu/document-register/documents/spr2014.pdf (accessed 30 January 2017)

European Railway Agency (2016) Railway Safety Performance in the European Union [online] https://erail.era.europa.eu/documents/SPR.pdf (accessed 30 January 2017)

Filippini, R. and Silva, A. (2014) 'A modeling framework for the resilience analysis of networked systems-of-systems based on functional dependencies', Reliability Engineering and System Safety, May, Vol. 125, pp.82-91.

Gerdun, V., Sedmak, T., Šinkovec, V., Kovše, I. and Cene, B. (2007) 'Failures of bearings and axles in railway freight wagons', Engineering Failure Analysis, Vol. 14, No. 5, pp.884-894.

Hodge, V.J., O'Keefe, S., Weeks, M. and Moulds, A. (2015) 'Wireless sensor networks for condition monitoring in the railway industry: a survey', IEEE Transactions on Intelligent Transportation Systems, Vol. 16, No. 3, pp.1088-1106.

Institution of Mechanical Engineers (2015) [online] http://events.imeche.org/ ViewEvent? code $=$ C6269 (accessed 4 July 2017).

Karcanias, N. (2015) Systems Complexity: The Paradigm of System of Systems, Complexity Science Workshop, Systems and Control Research Centre, City University London [online] http://www.city.ac.uk/_data/assets/pdf_file/0010/280891/System-of-Systems.pdf (accessed 4 July 2015). 
Kyriakidis, M., Majumdar, A. and Ochieng, W.Y. (2015) 'Data based framework to identify the most significant performance shaping factors in railway operations', Safety Science, Vol. 78, pp.60-76.

Leveson, N. (2011) Engineering a Safer World: Systems Thinking Applied to Safety, MIT Press.

Lloyd's Register Foundation (2015) Foresight Review of Structural Integrity and Systems Performance [online] http://www.lrfoundation.org.uk/publications/structural-integrity-andsystems-performance.aspx (accessed 24 July 2017).

Meixedo, A., Gonçalves, A., Calçada, R., Gabriel, J., Fonseca, H. and Martins, R. (2015) 'On-line monitoring system for tracks', in Experiment@International Conference (exp. At'15), 2015 3rd, IEEE, June, pp.133-134.

Palo, M., Lin, J. and Larsson-Kraik, P. (2013) 'Maintenance performance improvement for rolling stock wheels', Chem. Eng. Trans., Vol. 33, pp.727-732.

Sheikhalishahi, M., Pintelon, L. and Azadeh, A. (2016) 'Human factors in maintenance: a review', Journal of Quality in Maintenance Engineering, Vol. 22, No. 3, pp.218-237.

Singh, S. and Kumar, R. (2015) 'Evaluation of human error probability of disc brake unit assembly and wheel set maintenance of railway bogie', Procedia Manufacturing, Vol. 3, pp.3041-3048.

Sousa-Poza, A., Kovacic, S. and Keating, C. (2008) 'System of systems engineering: an emerging multidiscipline', International Journal of System of Systems Engineering, Vol. 1, Nos. 1-2, pp.1-17.

The Joint Sector Group (2012) Final Report on the Results of the Joint Sector Group Activities Linked to the Action Plan Defined under the Task Force Freight Wagon Maintenance [online] $\mathrm{https}$ :/www.google.co.uk/url? $\mathrm{sa}=\mathrm{t} \& \mathrm{rct}=\mathrm{j} \& \mathrm{q}=\& \mathrm{esrc}=\mathrm{s} \&$ source $=$ web\& $\mathrm{cd}=1 \& \mathrm{cad}=\mathrm{rja} \& u a c t=8$ \&ved=0ahUKEwiw8fOq5O_UAhUBDcAKHQuNAAUQFggoMAA\&url=http $\% 3 \mathrm{~A} \% 2 \mathrm{~F} \% 2 \mathrm{Fj}$ sgrail.eu\%2Fdownload.asp\%3Fitem id\%3D191\&usg=AFQjCNGUala9Gct 7u2mifwA8uaM Gjo6Gw (accessed 27 January 2017).

van Dongen L.A.M., (2015) Through-life Engineering Services: The NedTrain Case, Through-life Engineering Services: Motivation, Theory and Practice, Springer International Publishing, pp.29-55, ISBN 978-3319-12110-9.

Wallentin, M., Bjarnehed, H.L. and Lundén, R. (2005) 'Cracks around railway wheel flats exposed to rolling contact loads and residual stresses', Wear, Vol. 258, No. 7, pp.1319-1329.

Willcox, K., Allaire, D., Deyst, J., He, C. and Sondecker, G. (2011) Stochastic Process Decision Methods for Complex-Cyber-Physical Systems, Tech. Rep. ADA552217, Massachusetts Institute of Technology, Cambridge.

Zerbst, U., Mädler, K. and Hintze, H. (2005) 'Fracture mechanics in railway applications - an overview', Engineering Fracture Mechanics, Vol. 72, No. 2, pp.163-194.

Zhang, D., Hu, H., Liu, Y. and Dai, L. (2014) 'Railway train wheel maintenance model and its application', Transportation Research Record: Journal of the Transportation Research Board, No. 2448, pp.28-36.

\section{Notes}

1 In the literature, it can also be found as 'out-of-roundness'.

2 NS is the principal passenger railway operator in the Netherlands.

3 http://www.railway-technology.com/contractors/track/gotcha/. 